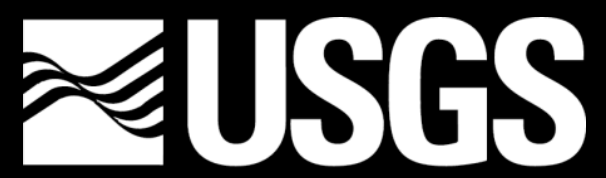

science for a changing world

\title{
USGS Asteroid Resource Assessments are Feasible
}

Laszlo Keszthelyi (Kestay)

lan Ridley, David Trilling (NAU), Larry Meinert, Justin Hagerty, Trudy King 


\section{Outline}

- Why do we care?

- The USGS "way"

- Feasibility study

- Discussion 


\section{This is the consistent goal of our Nation's space program}



MARS LANDING: HEADING FOR THE HIGH GROUND by Don Durda

- Why aren't we there yet? 


\section{Challenges for Humans to Mars}

- Long duration zero-g health effects

- Radiation in interplanetary cruise

- Heavy lift vehicle

- All can be solved with enough money

- How to reduce the cost? 


\section{Challenges for Humans to Mars}

- Long duration zero-g health effects

- Radiation in interplanetary cruise

- Heavy lift vehicle

- All can be solved with enough money

- How to reduce the cost?

- Don't bring much stuff from Earth

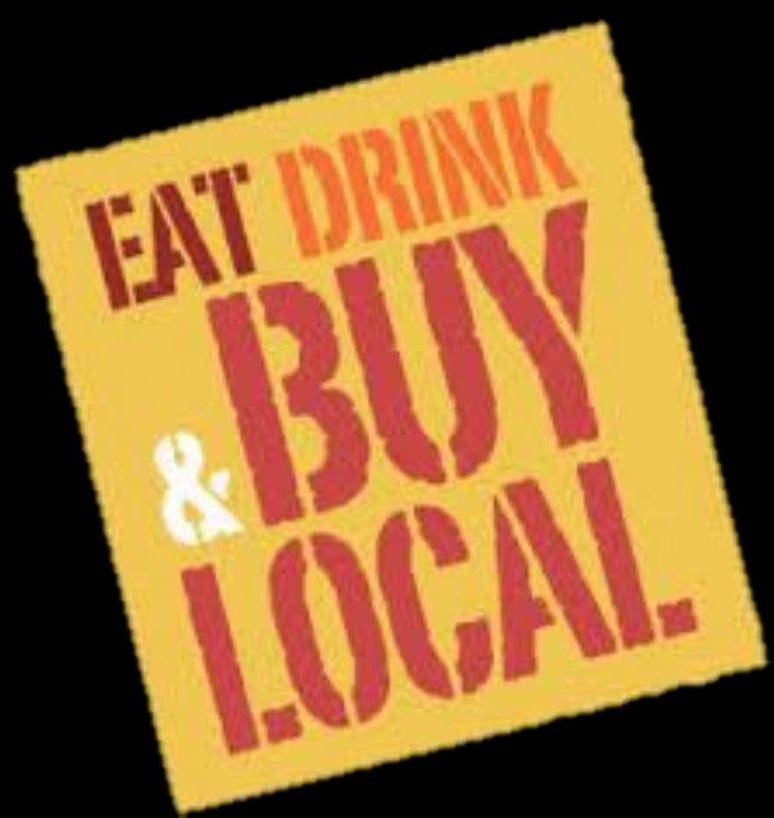




\section{But ISRU is not part of NASA's plan}

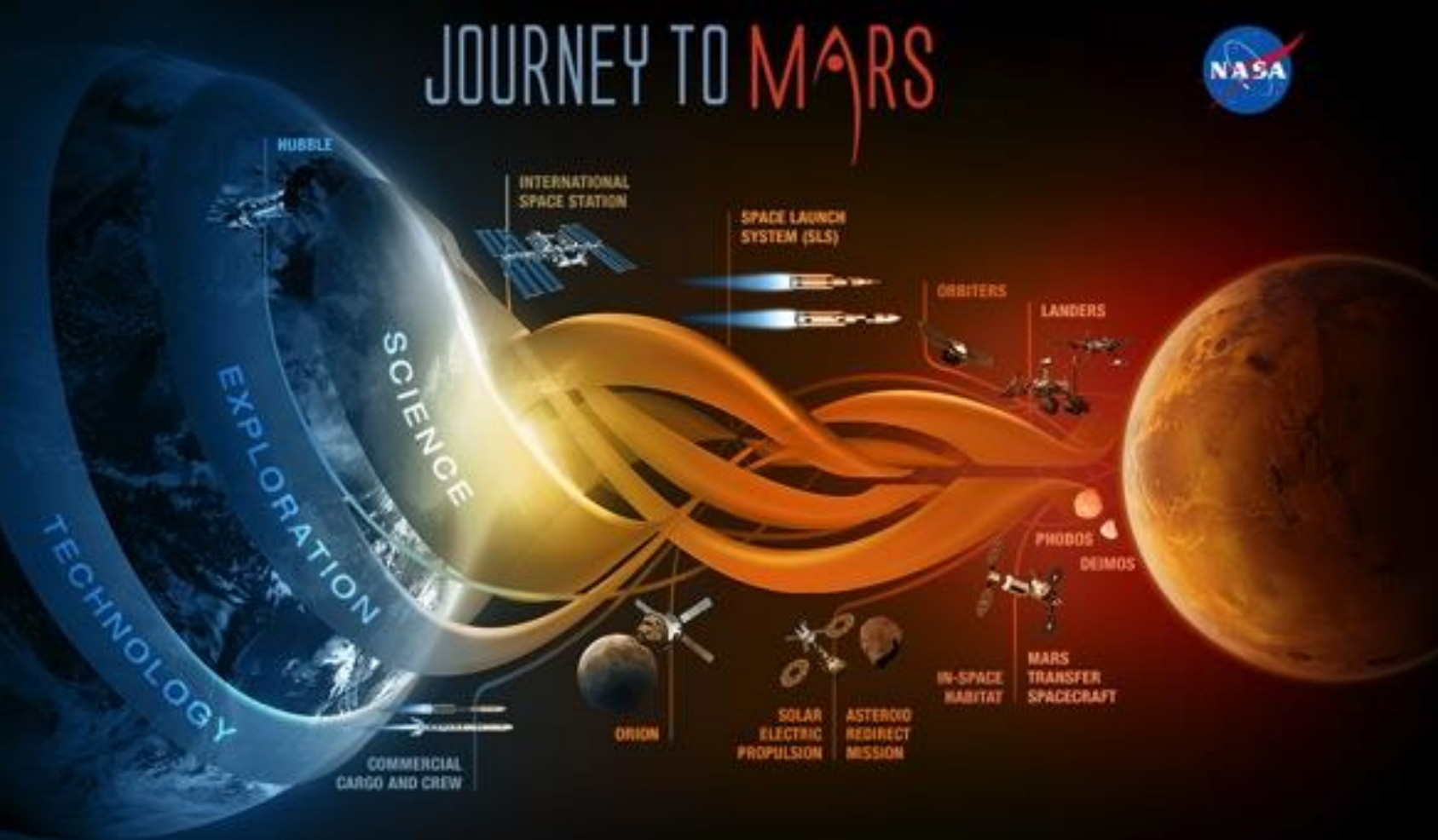

- Why not?

- Too much risk... 


\section{It is part of SpaceX's latest plan}

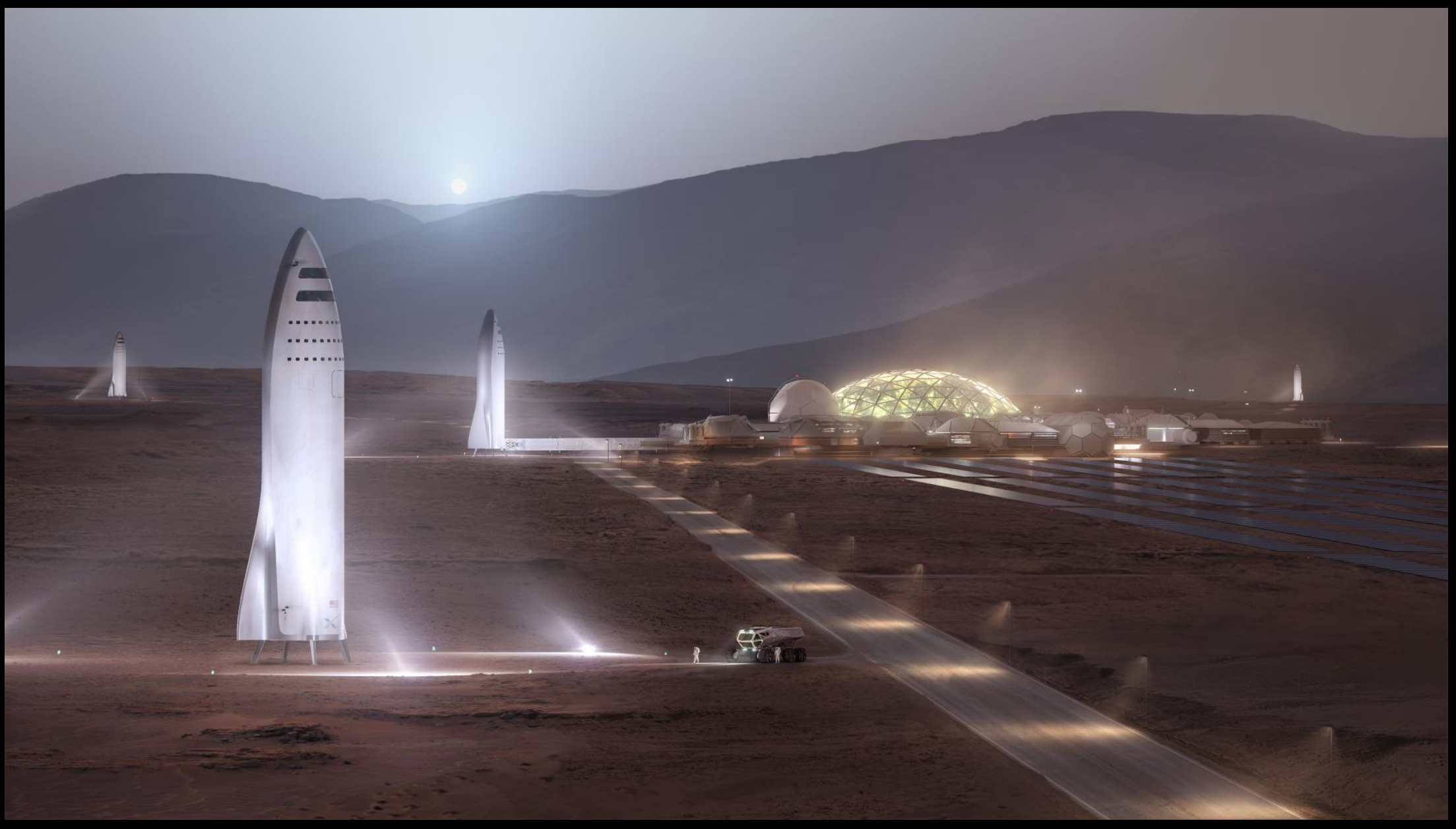

- But that doesn't make it any less risky! 


\section{What will reduce the risk?}

- Developing the technology to extract the resources - NASA and other are on it

- A demonstration - there is a small one on the Mars 2020 rover

- A trustworthy assessment of what is out there... 


\section{Who do you call when you want a reliable assessment of natural resources?}

WHO YOU GONNA CALL?

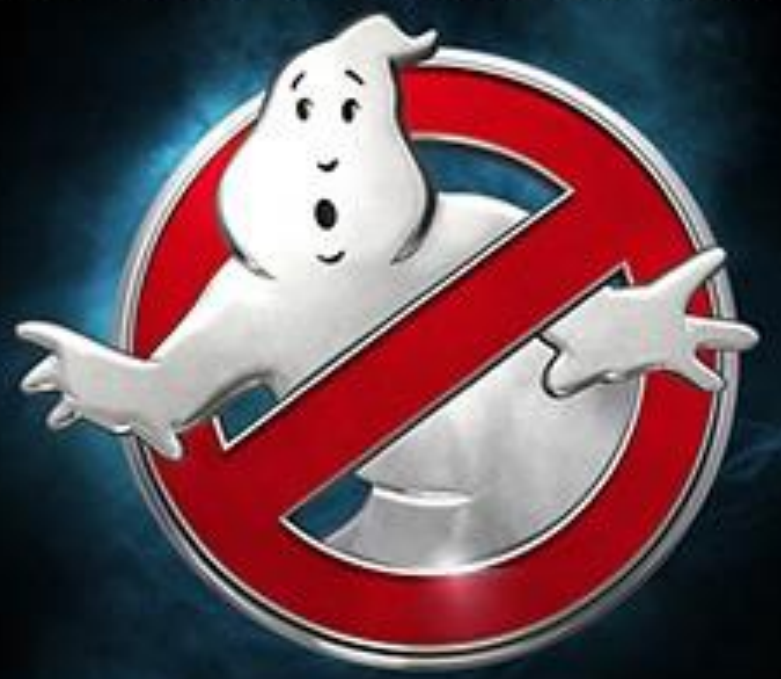


Who do you call when you want a reliable assessment of natural resources?

- The USGS has been tasked to assess resources since its inception in 1879

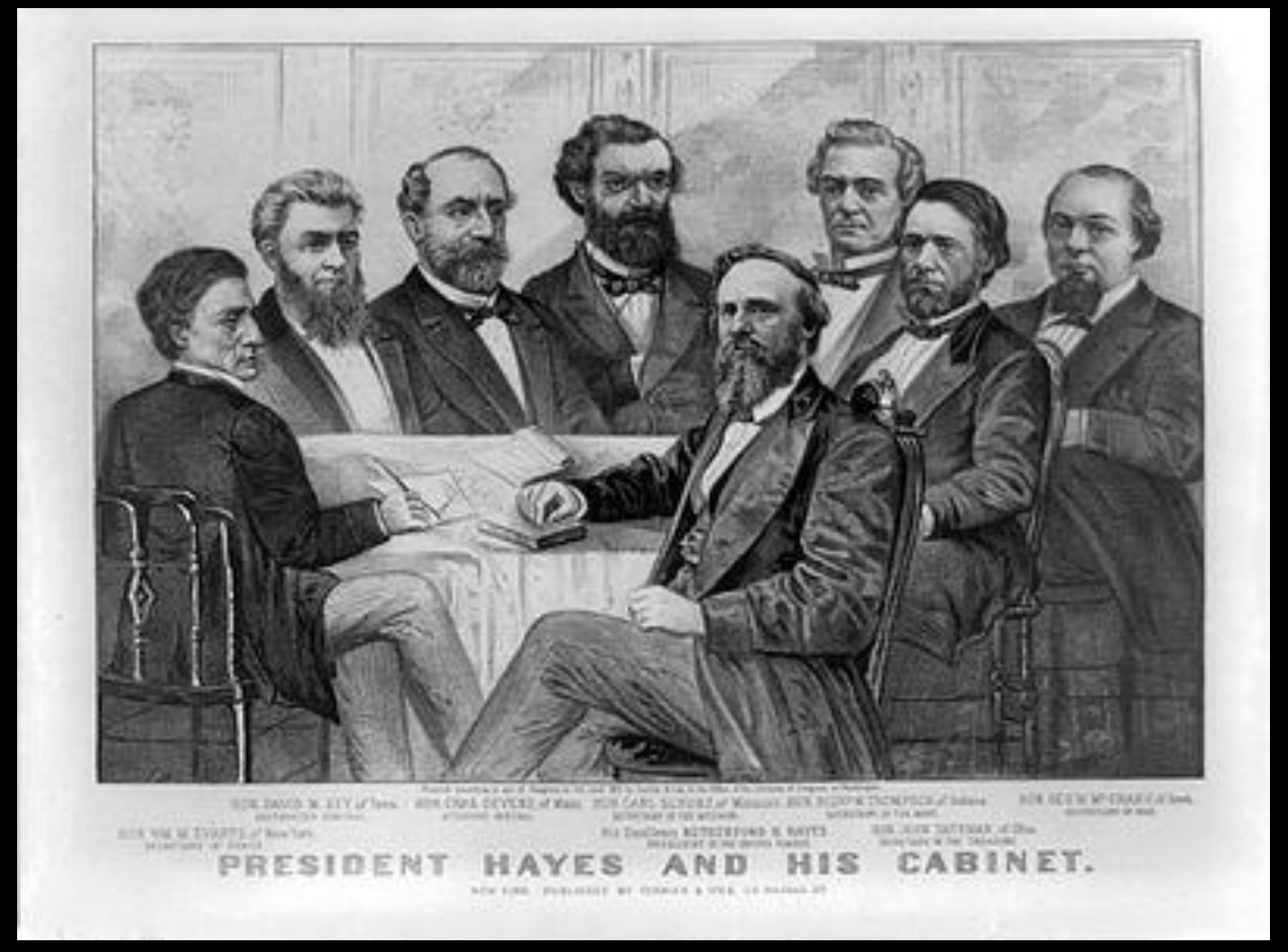




\section{Allows evidence-based decisions}

\section{Northern Alaska}

36 petroleum discoveries

$\sim 15 \mathrm{BBO}$ and 45 TCFG recoverable commercial production

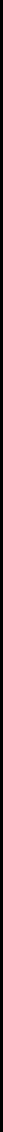




\section{How does the USGS do resource assessments?}

- Key properties of USGS assessments:

- Unbiased

- Quantitative

- Easy to understand by non-scientists

- Composed of 5 parts (called 3-part)

- Descriptive Model of resource deposits

- Spatial Model of study area

- Deposit-Density Model of deposits in study area

- Grade-Tonnage Model of deposit population

- Economic Model 


\section{How does the USGS do resource assessments?}
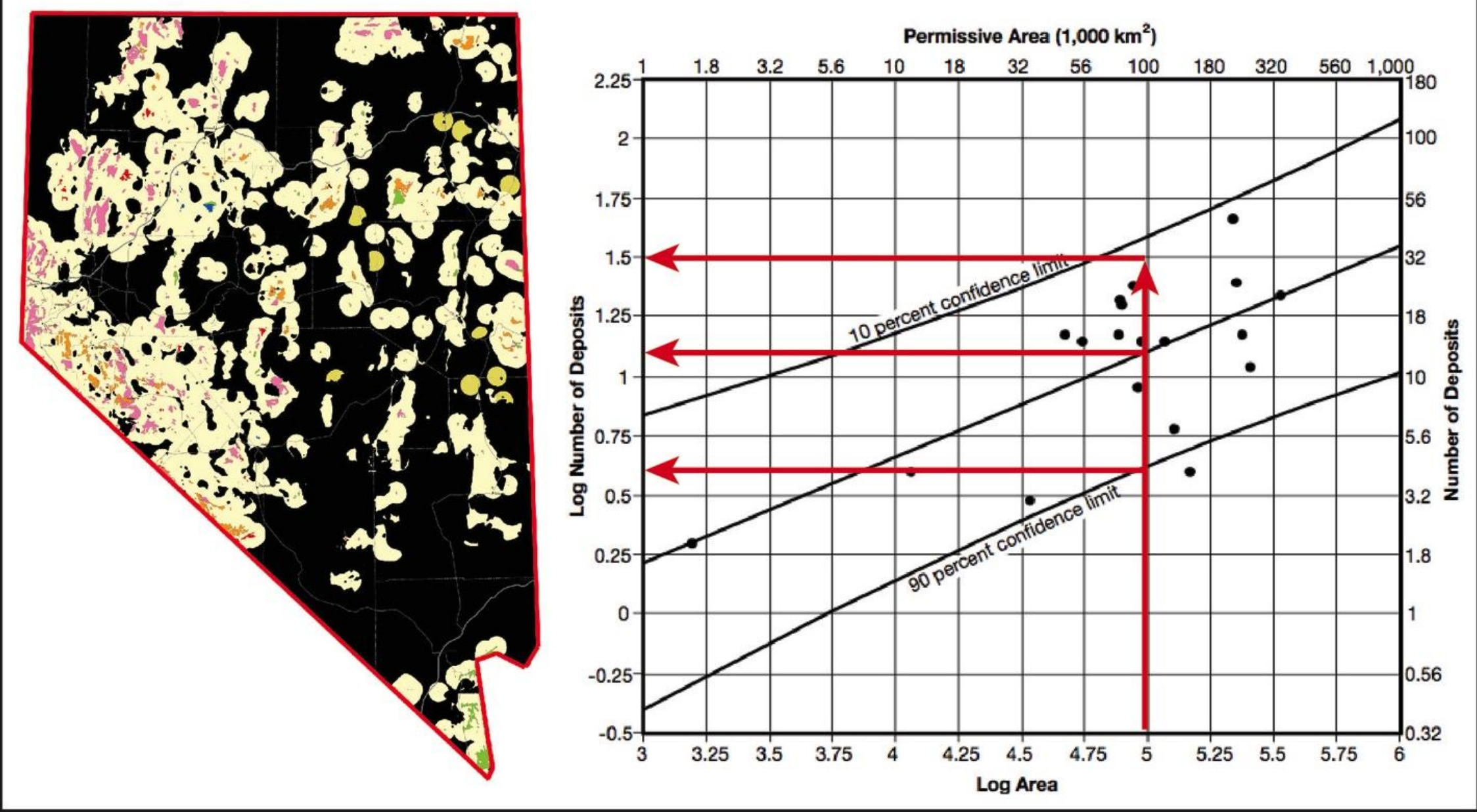

\section{\#USGS}




\section{How does the USGS do resource assessments?}
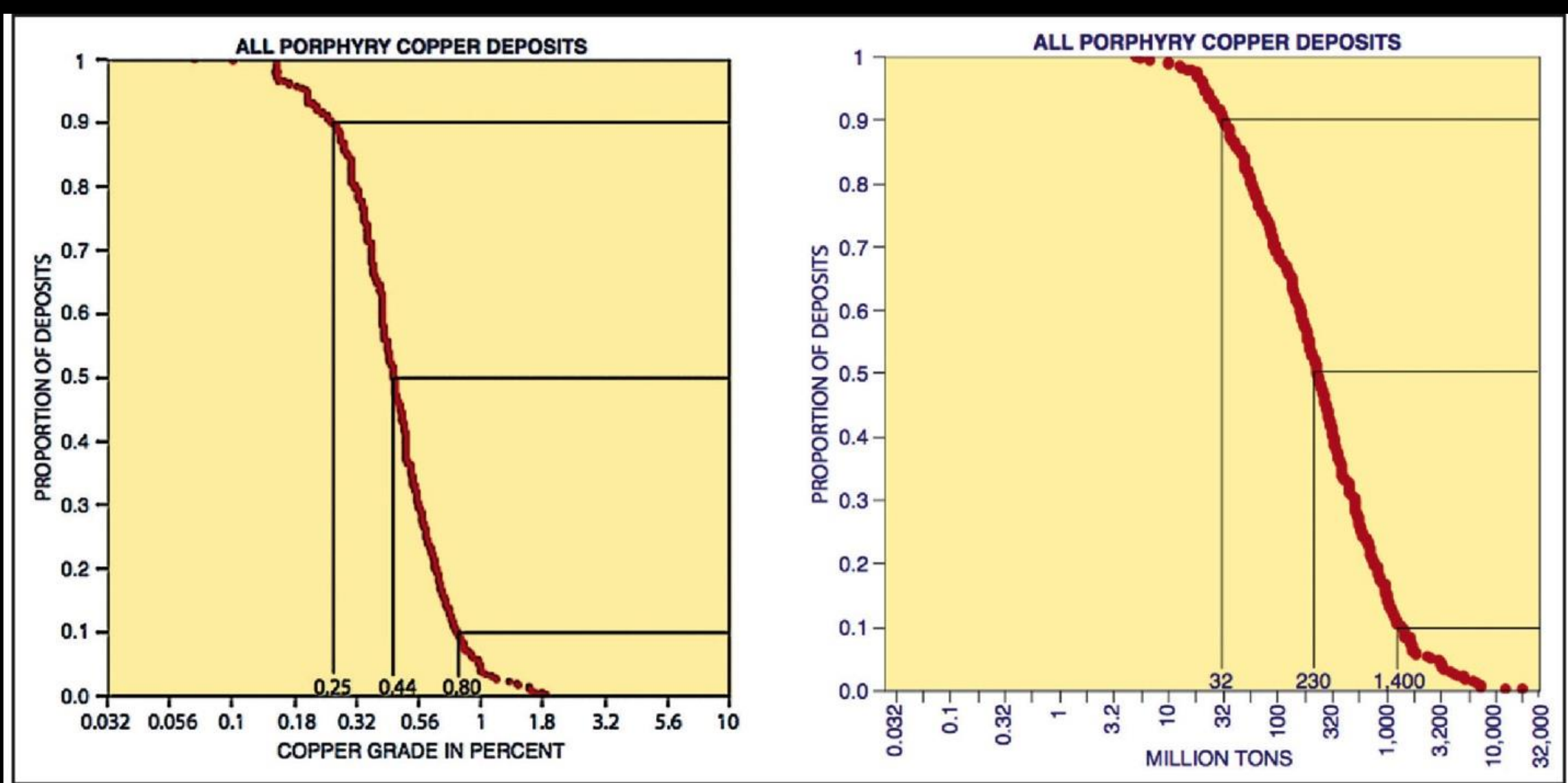

\section{‡USGS}




\section{USGS Feasibility Study}

- In FY16 the USGS Minerals Program funded the "ASTRA" project to investigate the feasibility of applying the USGS methods to asteroids

- Goal was not to produce a usable assessment

- Expected to identify future studies needed to do a proper assessment

- Did not attempt an economic model 


\section{Descriptive Model}

- Each asteroid is a "deposit"

- Considered 3 types of deposits:

- $\mathbf{C}=$ Carbonaceous (all carbonaceous chondrites)

- $\mathbf{M}=$ Metal-rich (irons and pallisites)

- $\mathbf{S}=$ Stony (everything else)
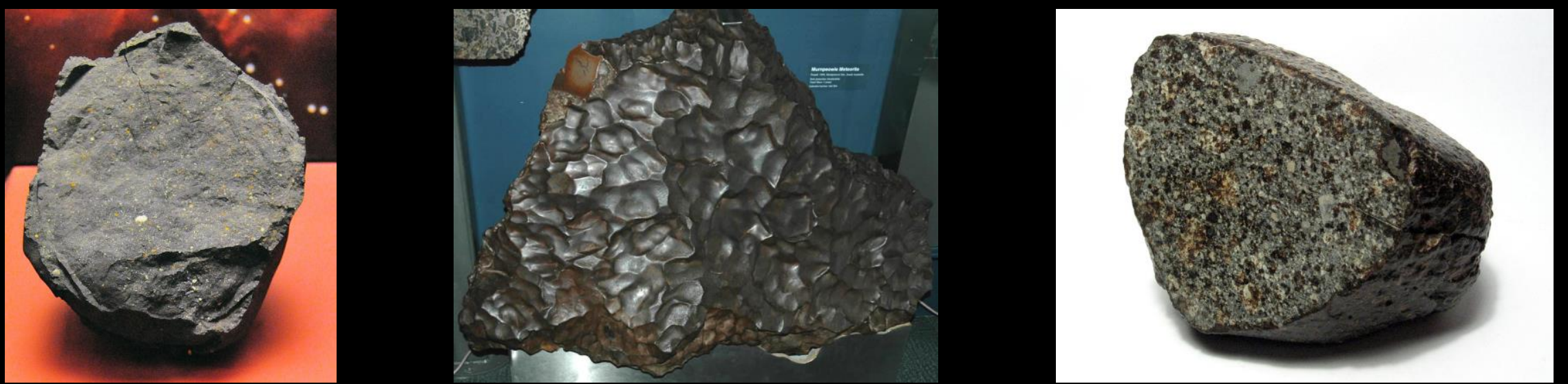


\section{Spatial Model}

Orbit Comparisons

- Restrict to NEOs with $\Delta v<7 \mathrm{~km} / \mathrm{s}$

- Same objects that are subjected to intense search for potential hazards

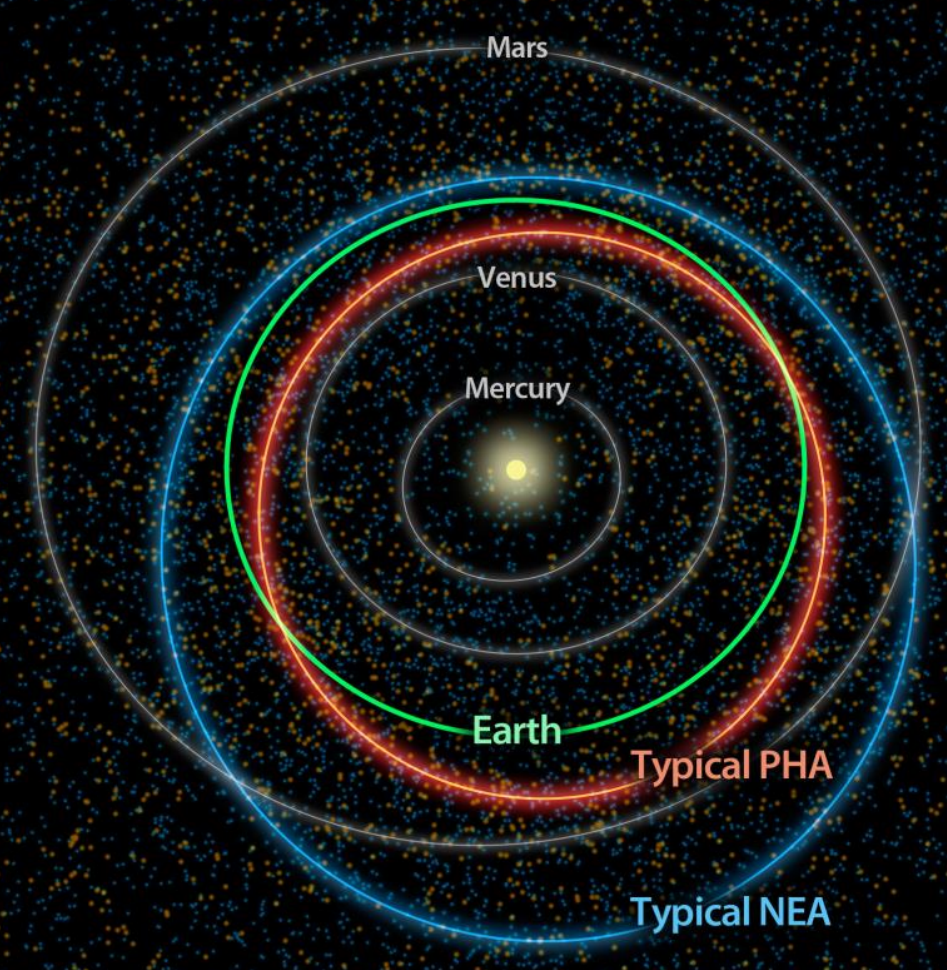




\section{Deposit-Density Model}

- Catalog of objects $>1 \mathrm{~km}$ in diameters is thought to be $\sim 95 \%$ complete - focus on them

- Data available from the Minor Planets Catalog

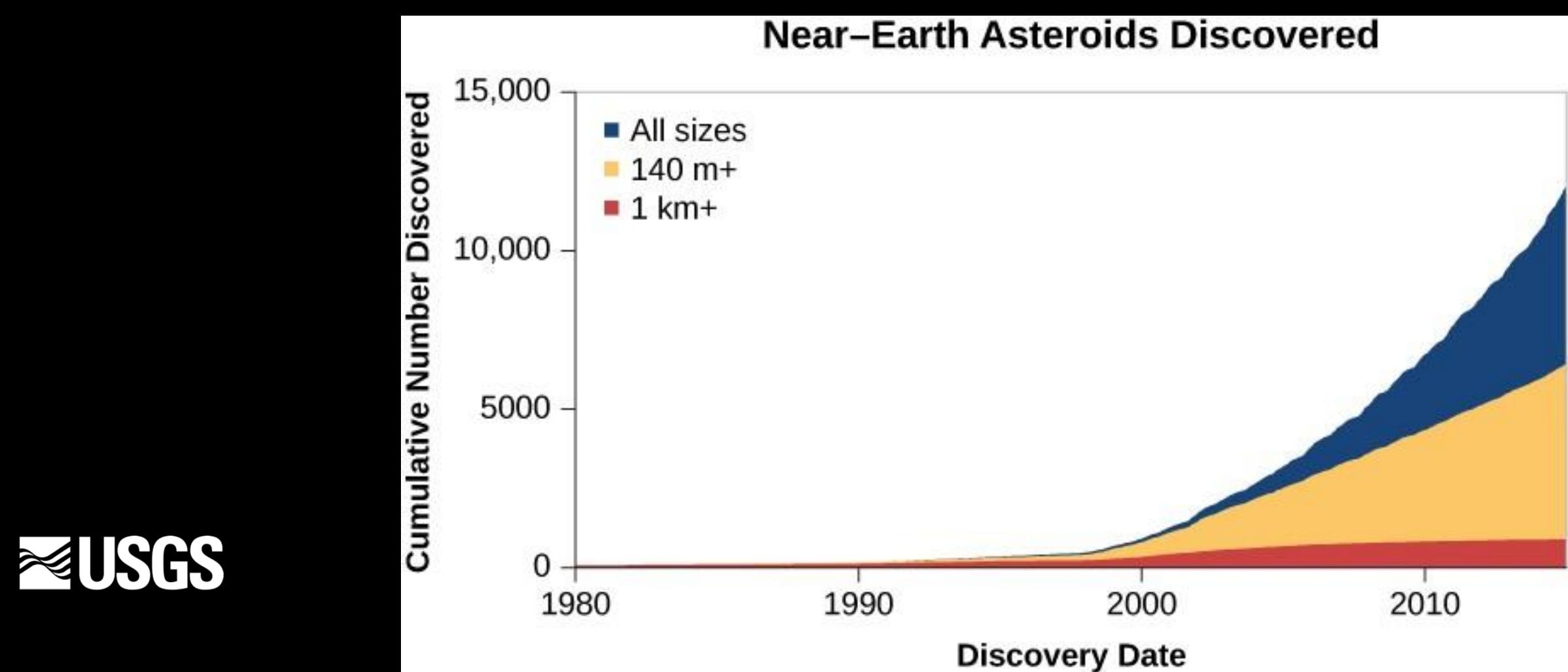




\section{Deposit-Density Model}

- Assume C, M, and S objects are "well mixed".

- Rely on SMASS spectra to estimate the fraction that are $\mathrm{C}, \mathrm{M}$, and $\mathrm{S}$

\begin{tabular}{|l|l|}
\hline \multicolumn{1}{|c|}{ Assumed Meteorite Group } & \multicolumn{1}{c|}{$\begin{array}{c}\text { SMASS Spectral Type from } \\
\text { Binzel and others (2004) }\end{array}$} \\
\hline Stony & $\begin{array}{c}\text { A, K, K:, L, Ld, O, Q, R, S, S:, S(IV), Sa, Sk, Sl, } \\
\text { Sq, Sq:, Sr, U, V, V: }\end{array}$ \\
\hline Carbonaceous & B, C, C:, Cb, Cg, Ch, D, T \\
\hline Metal-rich & $\mathrm{X}, \mathrm{X}:, \mathrm{Xc}, \mathrm{Xe}, \mathrm{Xk}$, \\
\hline
\end{tabular}

- If no SMASS data, assume $27 \%$ C, $34 \% M$, $39 \%$ S (Stuart \& Binzel 2004)

\#USGS 


\section{Grade-Tonnage Model}

- Consider grade and tonnage separately

- Tonnage model:

- Volume estimated from brightness (i.e., magnitude $\left.\left(M_{v}\right)\right)$ of the object and albeo

- Well-known that C's are much darker than the S's and M's but very few objects measured quantitatively. (We use $5 \%$ for $\mathrm{C}, 20 \%$ for $M$ and $S, \pm 50 \%$ )

- Mass requires knowledge of density

- Poorly known, use Carry (2014) study

- $>99 \%$ of the mass is in objects $>1 \mathrm{~km}$ in diameter $\left(\sim M_{v} 18\right)$ 


\section{Tonnage Model}

Composition
Group

\section{Compositi
Group}

\section{Minimum \\ Density}

$1468 \mathrm{~kg} / \mathrm{m}^{3}$

$577 \mathrm{~kg} / \mathrm{m}^{3}$

$1391 \mathrm{~kg} / \mathrm{m}^{3}$
Mean Density

$2704 \mathrm{~kg} / \mathrm{m}^{3}$

$2086 \mathrm{~kg} / \mathrm{m}^{3}$

$3482 \mathrm{~kg} / \mathrm{m}^{3}$
Maximum Density
Carbonaceous

\section{Metal-rich}

Stony 


\section{Grade Model}

- Grade model based on meteorite samples

- There is no database of meteorite samples

- Closest is a compilation by Nittler et al. (2004)

- There are no systematic measurements of whole rock compositions of meteorites

- Most studies focus on a few elements/isotopes

- Inter-lab/method calibrations limited

- Statistics based on number of samples analyzed, not mass of objects in space

\section{\#USGS}




\section{Grade Model}

Metallic Iron in Carbonaceous Meteorites

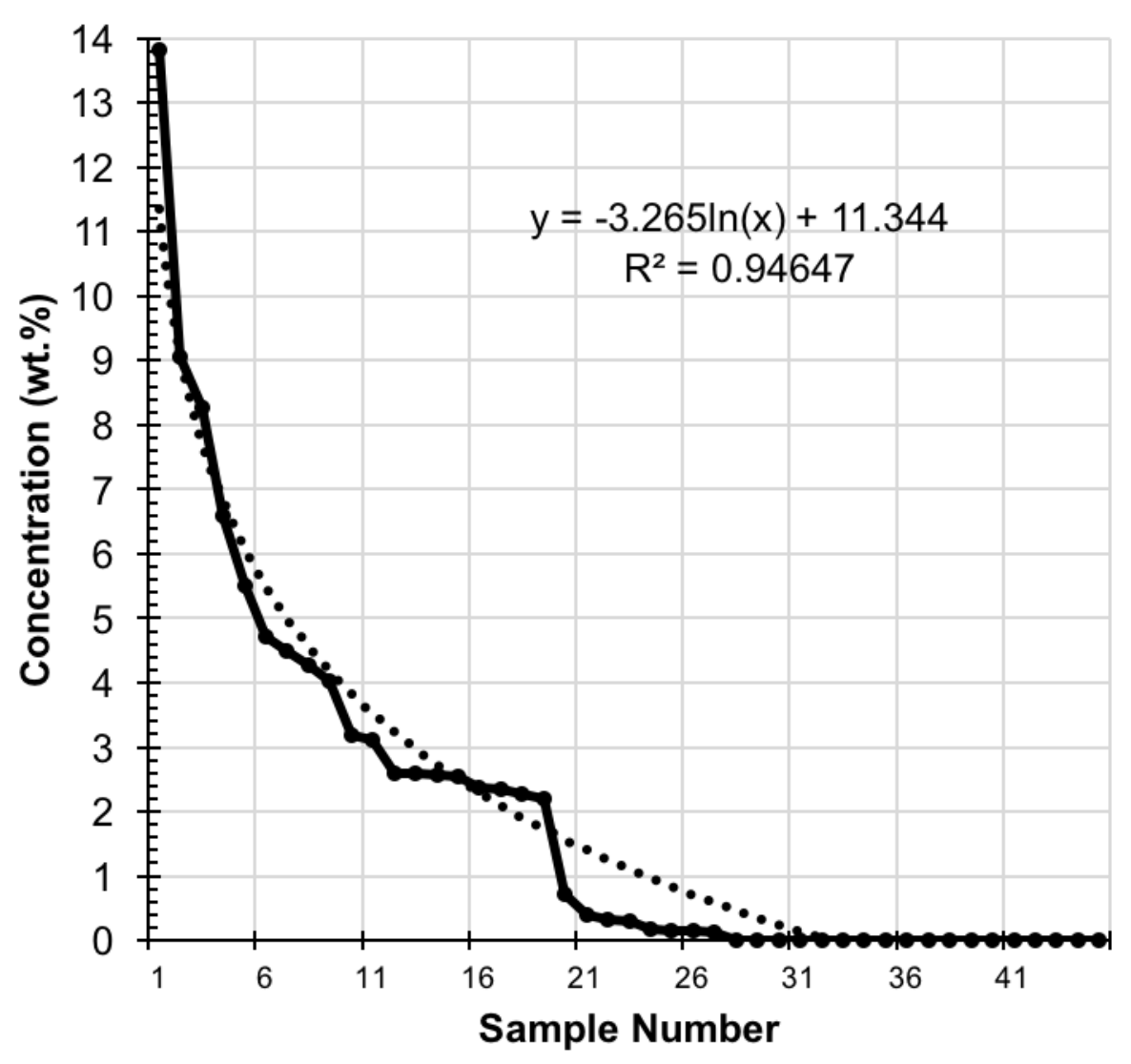

\section{Metallic Iron in Metallic Meteorites}

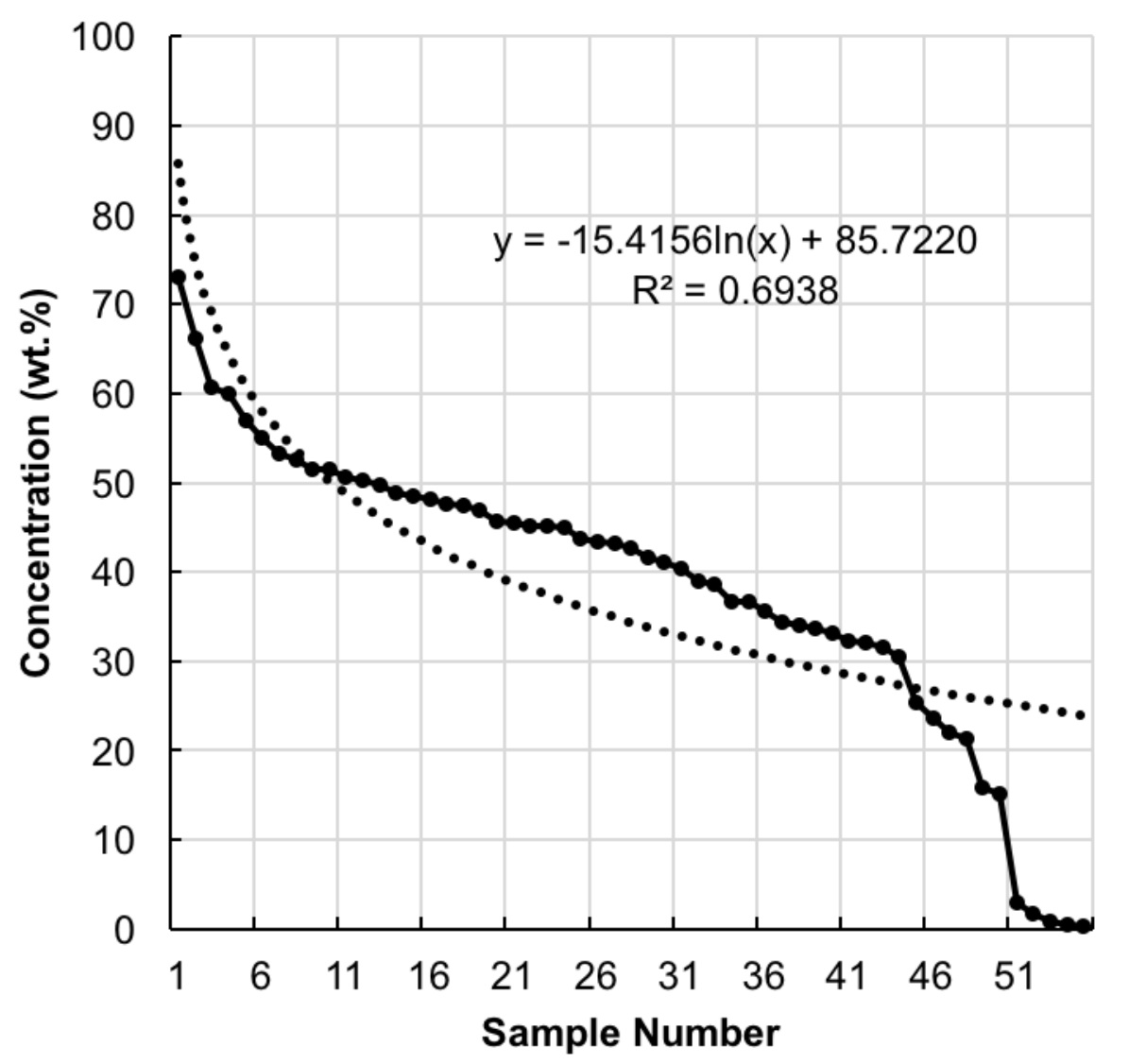

\section{₹USGS}




\section{Grade Model}

Water in Carbonaceous Meteorites

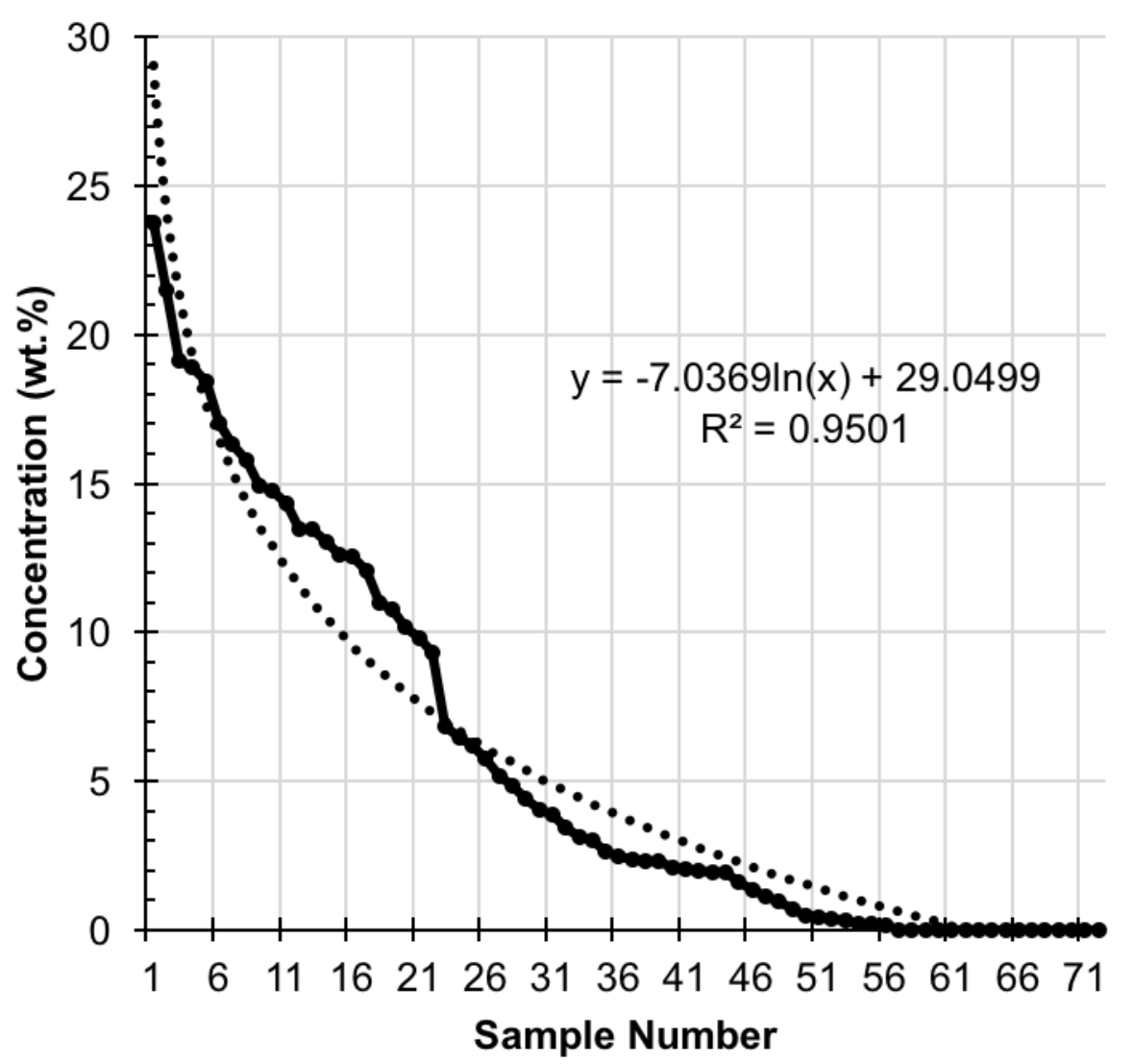

Water in Metallic Meteorites

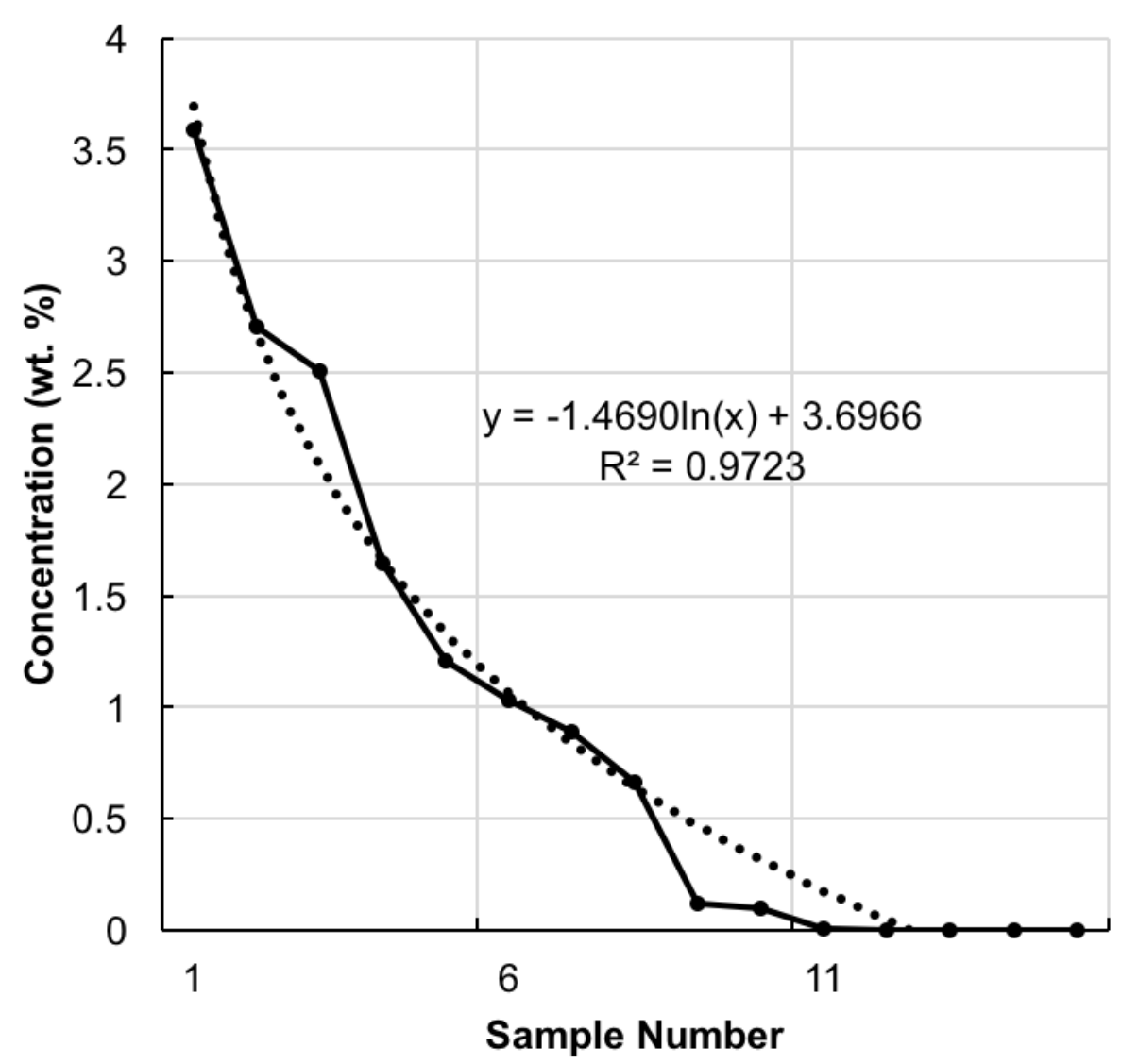

\section{₹USGS}




\section{Grade Model}

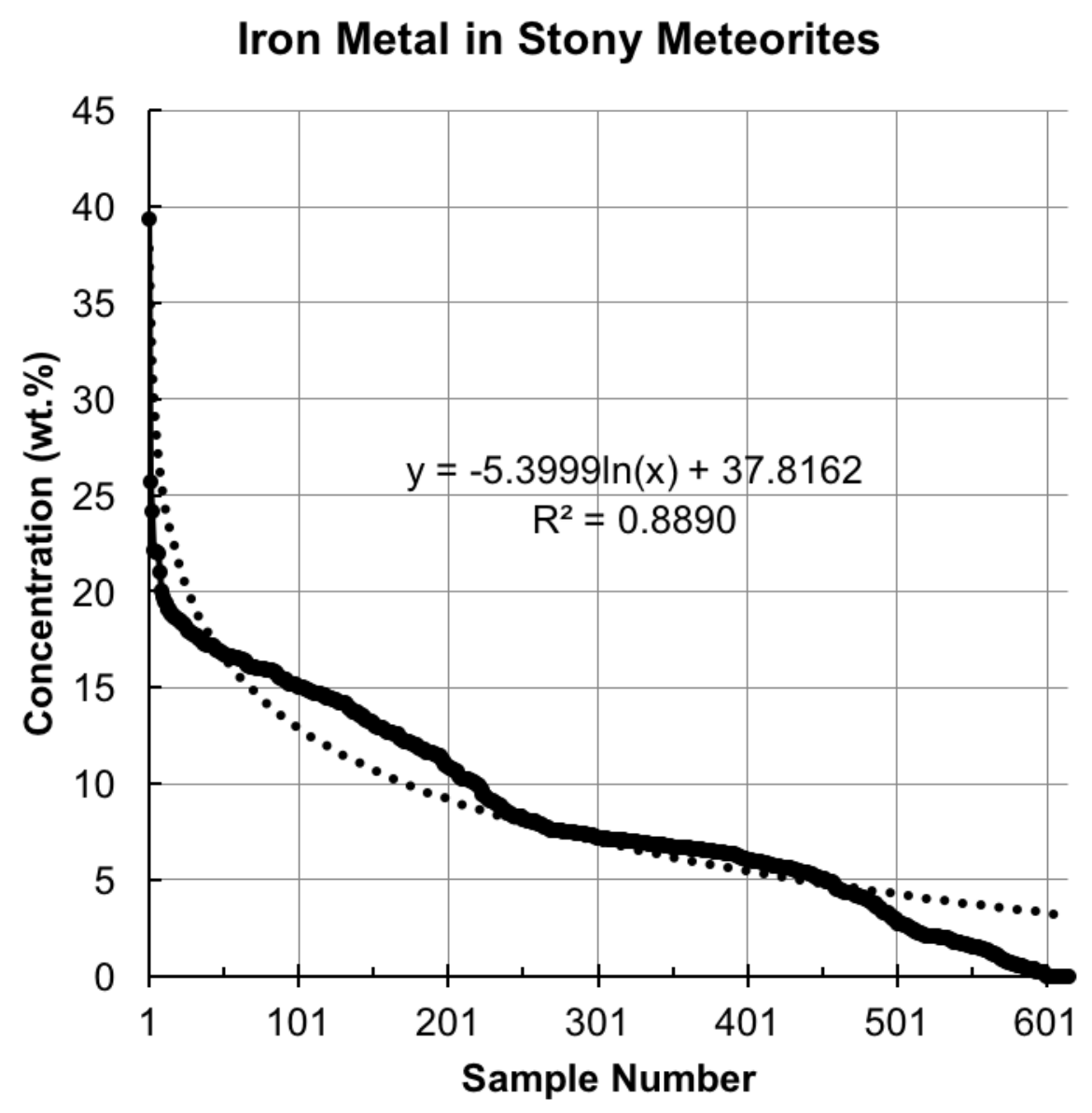

Water in Stony Meteorites

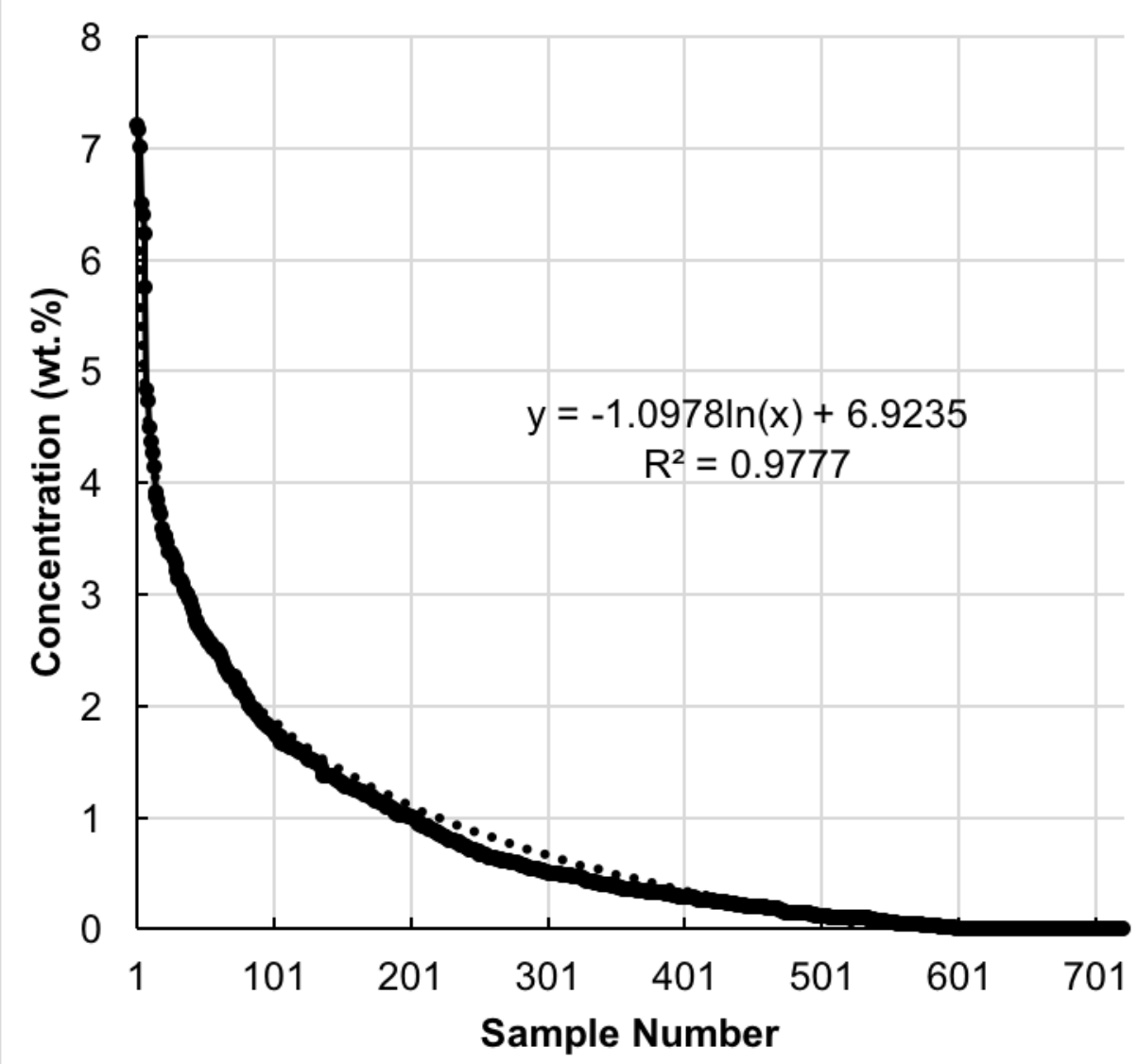

\section{\#USGS}




\section{Monte Carlo Model}

- Simple FORTRAN program run 100,000 times

- Ingest data on the $\mathbf{4 2 8}$ objects with Dv $<7 \mathrm{~km} / \mathrm{s}$ and $\mathrm{M}_{\mathrm{v}}<18$

- Add undiscovered objects (up to 43) and assign an $M_{v}$ to each

- Assign spectral class to unclassified objects

- Calculate volume and mass for each object

- Assign concentration of $\mathrm{H}_{2} \mathrm{O}$ and Fe-metal

- Sum the amount of $\mathrm{H}_{2} \mathrm{O}$ and Fe-metal

\section{¿USGS}




\section{Results}
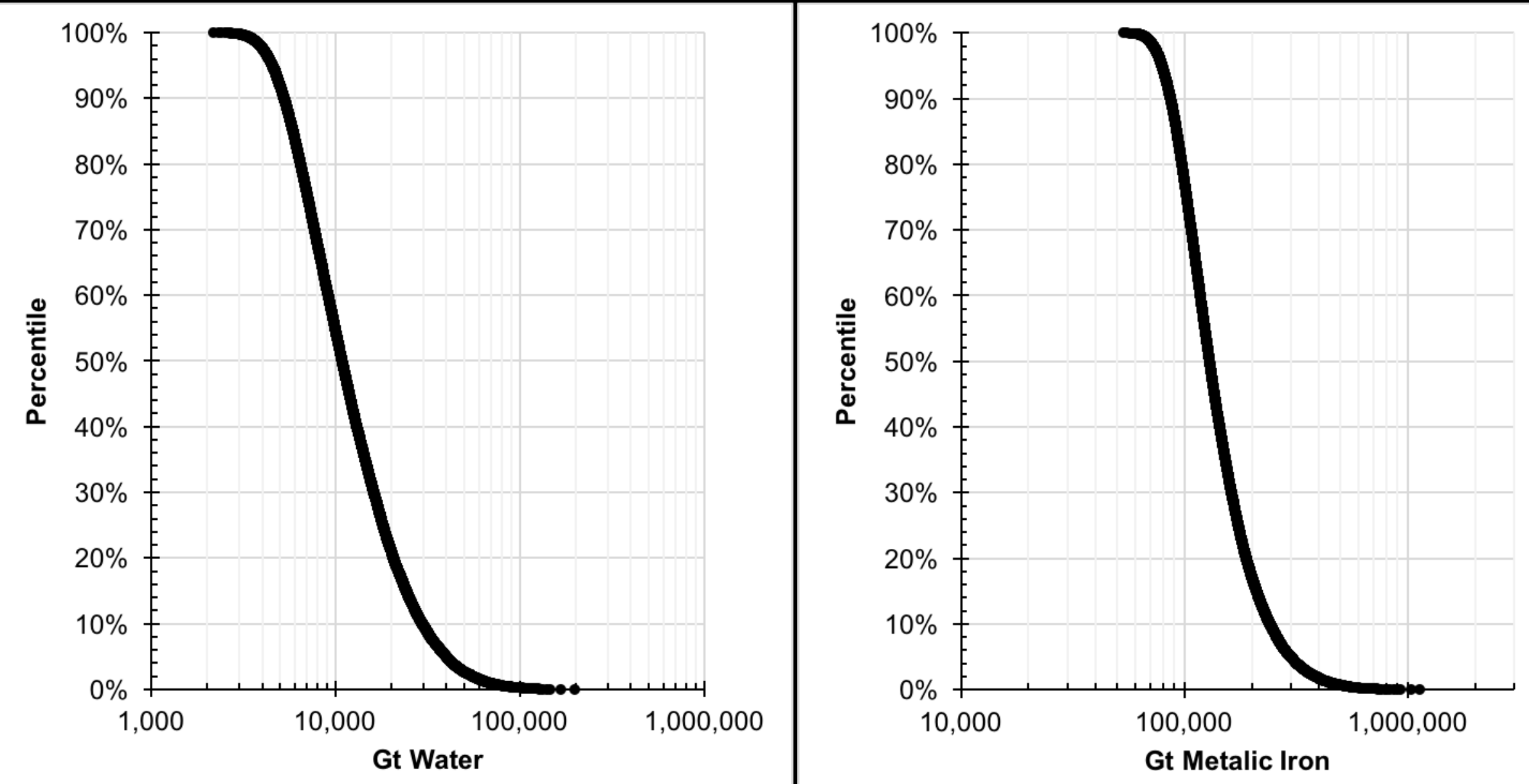

\section{\#USGS}




\section{Results}

- Compared to the ISS activities, the amount of water and iron in NEOs would sustain a million-fold increase for a million years ( \pm a few orders of magnitude)

- The most obvious problem is that, today, we have the technology to extract precisely none of this - but that is not the USGS's concern 
To do a real assessment we need to

- Better understand the distribution of different classes of NEOs

- Need more telescopic spectral observations

- Improve our ability to link spectra of NEOs to meteorites

- Need better laboratory studies + more missions

- Better understand the composition of each class of meteorite

- Need systematic lab measurements

\section{¿USGS}




\section{Conclusion of Feasibility Study}

- The USGS resource assessment methodology can be applied to asteroids

- There are three priority areas of research needed to complete a useful assessment

- Despite huge and unquantified uncertainties, we can confidently state that there are vast quantities of useful resources even in just the NEO population that could be extracted with appropriate future technology

\section{\#USGS}




\section{A small step toward this!}

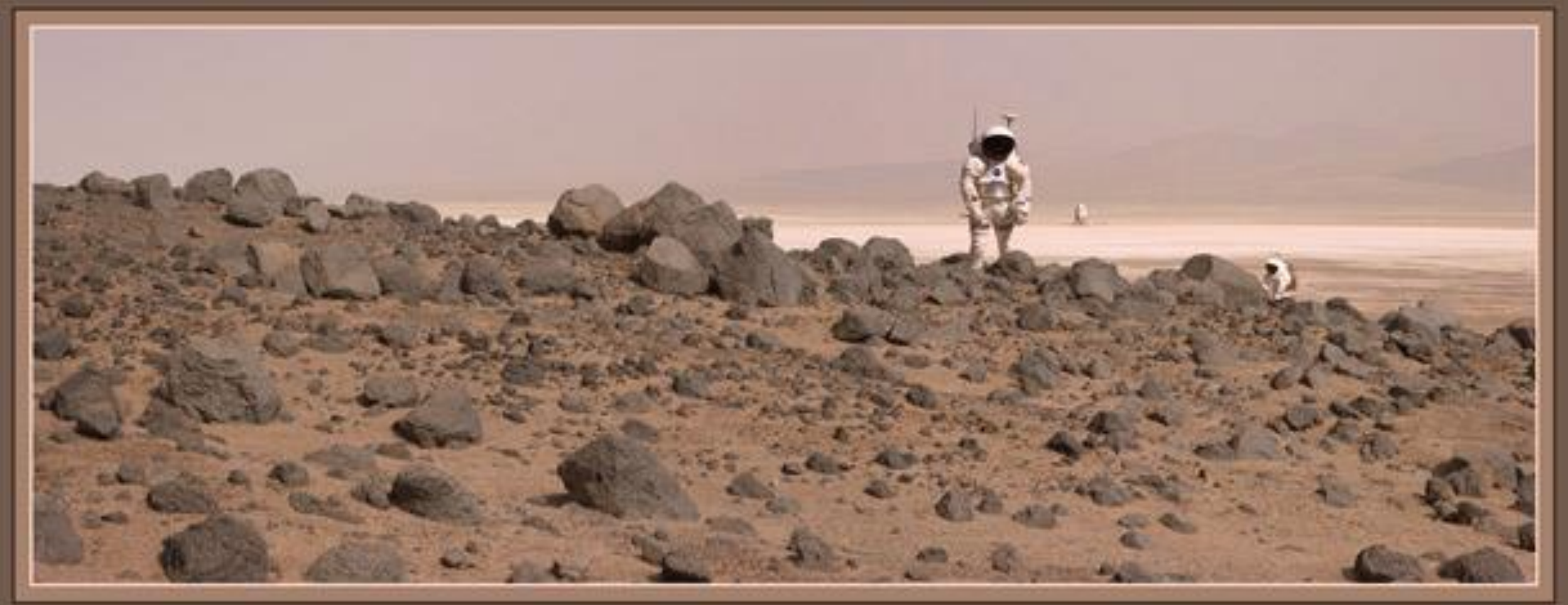

MARS LANDING: HEADING FOR THE HIGH GROUND by Don Durda

\section{\#USGS}

